\title{
A. Akhaddar (ed): Cranial osteomyelitis: diagnosis and treatment
}

\author{
Springer International Publishing Switzerland 2016, 325 pp., 162 figs. of which 81 are in \\ color (ISBN 978-3-319-30266-9, eBook ISBN 978-3-319-30268-3). Hardcover 109.99 €, \\ eBook $91.62 €$
}

\author{
Ahmet T. Turgut ${ }^{1} \cdot$ Mehmet Turgut $^{2}$
}

Received: 18 October 2016 / Accepted: 2 November 2016 / Published online: 11 November 2016

(C) Springer-Verlag Berlin Heidelberg 2016

During our entire professional career in the last two to three decades at different centers in Turkey, we encountered only a few cases of cranial osteomyelitis in our clinical practice. At present, there is no doubt that the title of the book may be "unusual" for many young specialists having been involved in the care of patients with infectious diseases in the developed countries. Nevertheless, cranial osteomyelitis is still an important problem in the remaining parts of the world because of the difficulties in management, the problem of drug resistance, and cost of the new antibiotics, which has been reviewed in this book by Professor Ali Akhaddar.

This unique reference book is well organized into six main parts containing a total of 16 chapters: four following the introduction (which includes definitions and historical aspects) related to basic information (epidemiology and risk factors, pathogens, histopathologic findings, and

Mehmet Turgut

drmturgut@yahoo.com

1 Department of Radiology, Hacettepe University Hospitals, Ankara, Turkey

2 Department of Neurosurgery, Adnan Menderes University Hospital, Aydin, Turkey pathophysiology of infection), four about the diagnosis (clinical findings, laboratory findings, imaging studies, and differential diagnoses), four concerning patient management (surgical therapy, antimicrobial and medical therapy, hyperbaric oxygen therapy, and outcome), two comprising special conditions (unusual pathogens and special clinical situations), and the remaining one related to prevention, even though there is some overlapping between various chapters. There are 16 chapters including the introduction. The first chapter is named "introduction, definitions and historical aspects." In this book, each chapter concludes with a list of references and a bibliography that ranges from historic articles to the most recent work. We believe that this book, with huge number of amazing illustrations, ranks among the most important scientific works on the topic, taking into account the fact that good quality illustrations - surgical photographs, radiologic images, and beautiful artwork - are apparently essential for such a surgery book. Despite being relatively specific, it sets the standard very high and fully fulfills the gap in our libraries.

Although there are a dozen books on various central nervous system infections all over the world, we strongly recommend this unique work as a practical and quick source of information for all pediatric neurosurgeons and neurologists, radiologists, and infectious disease consultants who feel a need to fill a gap in their knowledge base.

\section{Compliance with ethical standards}

Conflict of interest The authors declare that they have no conflicts of interest. 